\title{
Author Correction: Sas-4 provides a scaffold for cytoplasmic complexes and tethers them in a centrosome
}

\author{
Jayachandran Gopalakrishnan, Vito Mennella, Stephanie Blachon, Bo Zhai, Andrew H. Smith, \\ Timothy L. Megraw, Daniela Nicastro, Steven P. Gygi, David A. Agard \& Tomer Avidor-Reiss
}

Correction to: Nature Communications https://doi.org/10.1038/ncomms1367, published online 21 June 2011.

This article contains errors in Fig. 7. In Fig. 7b, the blot for the Sas-4 variant in the Sas-4-N190 panel is inadvertently duplicated from the Sas-4-N190 blot in the Sas4-N190 + Stripped Centrosomes panel. In Fig. 7c, the blot for Sas-4 in the CNN \& Asl \& $\Delta 90+$ Stripped Centrosomes panel is inadvertently duplicated from the Asl blot for the CNN \& Asl \& $\Delta 90+$ Stripped Centrosomes panel. The error has not been corrected in the PDF or HTML versions of the article.

Published online: 15 April 2020

(C) The Author(s), under exclusive licence to Springer Nature Limited 2020 
a
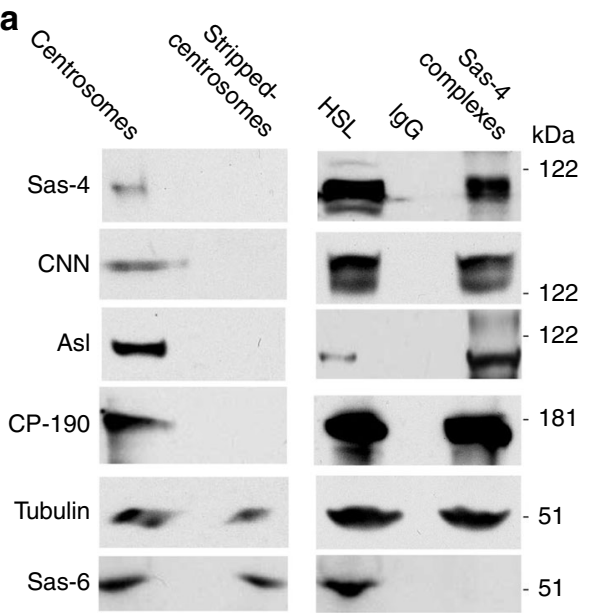

b
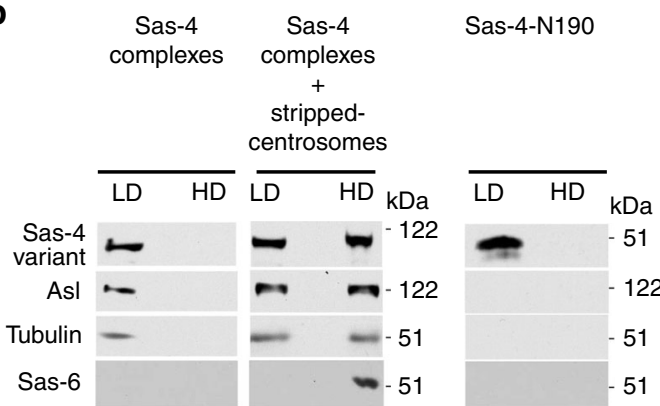

122

51

$-51$

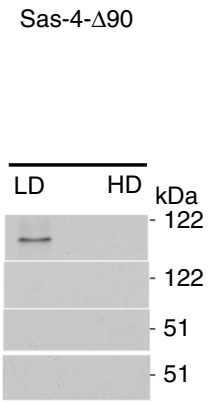

Sas-4-N190

$\stackrel{+}{\text { Stripped- }}$ centrosomes
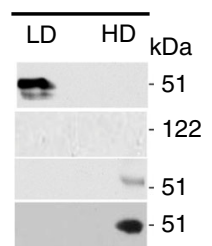

d

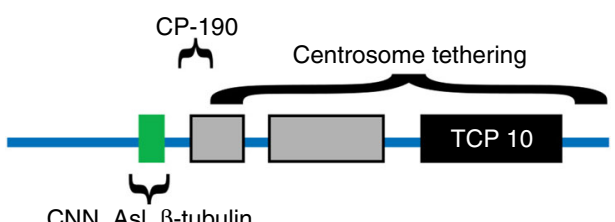

CNN, Asl, $\beta$-tubulin

D-PLP, $\gamma$-tubulin

$\circ$

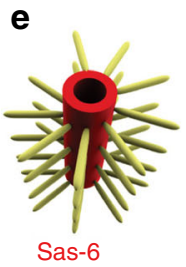

Nascent procentriole

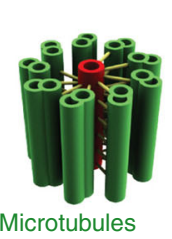

Procentriole

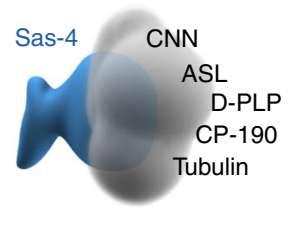

S-CAP complex

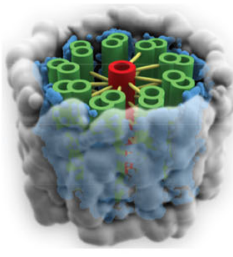

Centriole

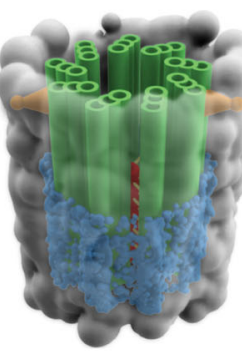

Elongated

centriole
Sas-4- $\Delta 90$

Strippedcentrosomes

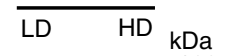

- 122
$-\quad-\quad$
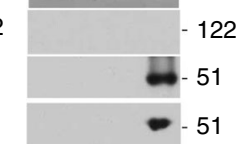

Fig. 7 